Review Article

\title{
THE BAEPENDI “LITTLE HEART” STUDY: strategies in child education related to cardiometabolic risk factors for reducing morbidity and mortality in a developing country
}

\begin{abstract}
Background: The Baependi Heart Study is the first studies in Brazil clustering families for analyze the relationship between genetic and cardiovascular risk factors. It had started in 2005 with partnerships among some Brazilian Universities for research and outreach projects. Ten years later, a new project was developed. It was related to child and adolescent education for prevention of cardiovascular risk factors in school, followed by local teachers who continued to disseminate health promotion, since the goal is to reduce noncommunicable chronic diseases, a major cause of global morbidity and mortality.

Method: The targeted audiences were county (local), state and private schools in the cities of Baependi, Juiz de Fora and Curitiba. In Baependi and Juiz de Fora, the focus is children from 4 to 12years old and our group have been promoting some activities: (1) A first talk to children to introduce a new Portuguese vocabulary and Sciences concepts (LDLcholesterol, HDL-cholesterol, blood pressure, insulin, diabetes, for example). (2) A puppet plays presentation. (3) A new discussion on the interdisciplinary aspects (healthy habits, science, physics, history, culture, literature, art and philosophy) related to points previously discussed and presented in the play. (4) Playful activities: songs, games, hands on making a fruit salad, for example and trying to make them real actors of a healthy life style and grow a conscience about it. In Curitiba, we trained teachers to work with their students using the same steps described.
\end{abstract}

Results: The project developed in schools reached a total of 9,592people.

Conclusion: It can be possible, rewarding and non-expensive to carry out projects for health promotion and prevention of diseases, mainly chronic non-communicable diseases, involving children, adolescents and adults, when there is a linkage of research, teaching, care, public policies.
Volume 5 Issue 5 - 2017

\author{
Beatriz Elizabeth Bagatin Veleda Bermudez,' \\ Rafael de Oliveira Alvim, ${ }^{2}$ Flávia Mesquita \\ Soares, ${ }^{3}$ Ana Beatriz Clemente Gonçalvez, ${ }^{3}$ \\ Edison Luiz Almeida Tizzot,' Anderson \\ Ulbrich,' Carlos Alberto Mourão Júnior, ${ }^{4}$ \\ Camila Maciel de Oliveira ${ }^{1,3,5}$ \\ 'Department of Preventive Medicine, Federal University of \\ Parana, UFPR, Brazil \\ ${ }^{2}$ Department of Public Health, Federal University of Espirito \\ Santo, UFES, Brazil \\ ${ }^{3}$ Faculty of Medicine of Juiz de Fora, UNIPAC, Brazil \\ ${ }^{4}$ Department of Physiology, Federal University of Juiz de Fora, \\ Brazil \\ ${ }^{5}$ Department of Preventive Medicine, Boston University, BU, \\ United States
}

\begin{abstract}
Correspondence: Camila Maciel de Oliveira, Department of Preventive Medicine, Federal University of Parana, UFPR, Faculty of Medicine of Juiz de Fora, UNIPAC, Department of Preventive Medicine, Boston University, BU, United States, Email camilamacieloliveira@gmail.com
\end{abstract}

Received: July 17, 2017 | Published: October 12, 2017

\section{Introduction}

The Baependi Heart Study is the first studies in Brazil clustering families for analyze the relationship between genetic and cardiovascular risk factors. ${ }^{1-6}$ It had started in 2005 with partnerships among some Brazilian Universities for research and outreach projects.

Then, ten years later, in March, 2015 a new project was developed and it couldn't be more promising. It was called The Baependi "Little Heart" Study. It was related to child and adolescent education for prevention of cardiovascular risk factors in schools of three different cities. Local teachers keep disseminating concepts related to health promotion after learning this method, since the goal is to reduce noncommunicable chronic diseases, a major cause of global morbidity and mortality have followed it.

The aim of this project was introduce concepts about prevention of some prevalent diseases in this country, improving physical activity and food inhabits, in a simple and cheap method to teach children about serious matter in a playful way.

\section{Methods}

We worked using puppets (named Insulin, Pancreas, Heart, Carrot and so on) to teach about prevention of cardiovascular diseases, healthy lifestyle, hygiene habits and prevention of epidemic diseases
(Figure 1). It was mean to be fun for the kids. We needed only the play designed for this purpose, puppets and a frame with a curtain. And sometimes a microphone and an amplifier, for a large audience. The method is flexible in a matter of how to work on it. Students of medical, nutrition, and nursey schools were responsible for developing of activities at school, and sometimes the actors holding the puppets behind scenario could be the children (Figure 2).

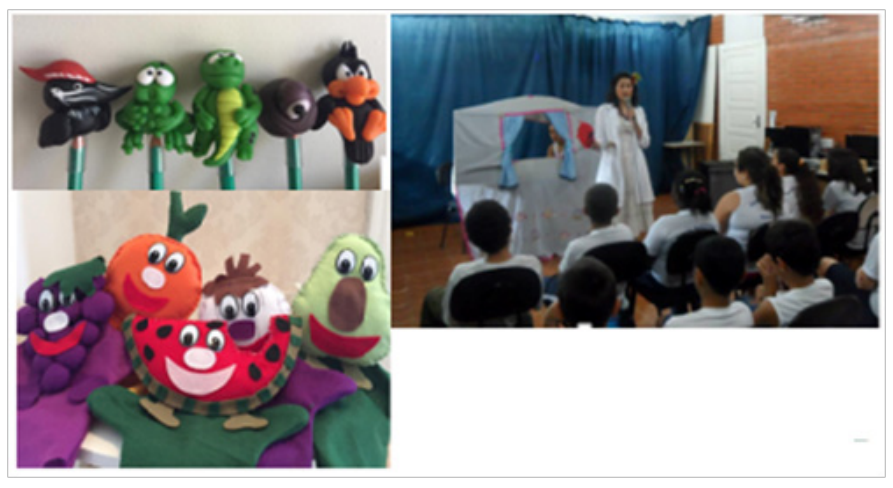

Figure I Pictures of the puppets and activities developt at fundamental schools. 


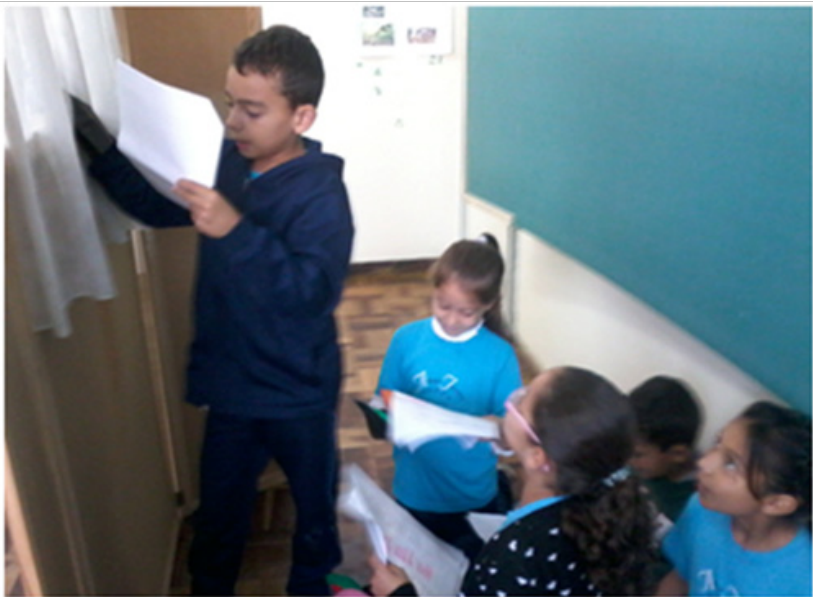

Figure 2 Students acted in the play presentation behind scenario.

The plays presented in 2015/2016 in Baependi, Juiz de Fora and Curitiba were: Stomach in love and a broken Heart; Fruit Salad in trouble; The Heart; Vitamin D and the little mice; Little Red Riding Hood and Diabetes; The girl and the baby teeth; Lulu, the caterpillar who didn't want to grow old; The firefly named Zezeca; The little fairy Luciferase and Not here, Mr. Aedes!

The targeted audiences are county, state and private schools in the cities of Baependi and Juiz de Fora, Minas Gerais State. We included children from 4 to 12years old and promoted: (1) A first talk to the children to introduce a new vocabulary and concepts (LDLcholesterol, HDL-cholesterol, blood pressure, diabetes, H1N1 virus, aedes aegypt); (2) A play presentation; (3) A new discussion on the interdisciplinary aspects (healthy habits, science, physics, history, culture, literature, art and philosophy) previously discussed and presented in the play; (4) Playful activities: songs, games, hands on making a fruit salad, for example and trying to make them real actors of a healthy life style and grow a conscience about it. Later we trained teachers to work with their students the same steps described.

In the same year, in Curitiba, Parana State, we started to train the teachers of county and state schools with the help of the local government. The idea is to train them in order to disseminate even more the method and expand the number of reached children. We also encouraged teachers to let the students be the active part in the play presentation. The results were very promising, since the children were starting to make their own puppets. It had been to present these plays for special education schools. The children were very participative and opened to this new subject.

\section{Results}

As we could see it is possible to educate a large number of people by using a little amount of money in order to prevent many of the known heart diseases. We spent approximately US\$200.00per month from Zerbini Foundation to spread the word to a total of 9,592children and adolescents in 23 schools and 10,182 presentations. The play presentation and number of schools and students are in Tables $1 \& 2$

Table I City, play presentation and number of students

\begin{tabular}{lll}
\hline City & Play presentation & Students \\
\hline Baependi & The stomach in love & 675 \\
Juiz de Fora & & 1434 \\
\hline
\end{tabular}

Table continued

\begin{tabular}{lll}
\hline City & Play presentation & Students \\
\hline Baependi & Fruit salad & 831 \\
Juiz de Fora & & 1615 \\
Curitiba & & 510 \\
Baependi & The Heart & 758 \\
Juiz de Fora & & 78 \\
Baependi & Red Little Hat & 580 \\
Juiz de Fora & & 1484 \\
Baependi & The baby teeth & 268 \\
Baependi & Lulu, the caterpillar & 998 \\
Baependi & Firefly Zezeca & 413 \\
Baependi & Not here, Mr.Aedes! & 538 \\
Total & & 10182 \\
\hline
\end{tabular}

Table 2 Education presentation in events

\begin{tabular}{|c|c|c|c|c|}
\hline Public & Specification & City & Activity & Public \\
\hline Professionals & Education & Curitiba & Fruit salad & 30 \\
\hline Patients & Diabetic & $\begin{array}{l}\text { Juiz de } \\
\text { Fora }\end{array}$ & $\begin{array}{l}\text { Fruit salad, } \\
\text { Red Little } \\
\text { Red }\end{array}$ & 144 \\
\hline Patients & Diabetic & $\begin{array}{l}\text { Juiz de } \\
\text { For a }\end{array}$ & The Heart & 56 \\
\hline Students & Deficiency & Curitiba & Cooking & 50 \\
\hline Total & & & & 280 \\
\hline
\end{tabular}

\section{Discussion}

Childhood overweight and obesity is an important public health issue in many countries. The prevalence of obesity has increased by $30 \%$ in the last 20years. Obesity increased from 7 to $18 \%$ in the population aged 6 to 11 years and from 5 to $21 \%$ in adolescents, constituting the most prevalent pediatric nutritional disease, but in a stable situation between 2003-2004 e 2011-2012. ${ }^{7-9}$ In Australia, 20$25 \%$ of children between 2-8years old are currently overweight or obese. $^{10}$

Overweight and obesity rates differed only slightly across children's age groups, ranging from $22.8 \%$ for children aged 2 to 4 years, to $26.6 \%$ for children aged 12 to 15 years. Adverse outcomes associated with childhood overweight and obesity includes poorer health, slower cognitive and social development and social isolation and discrimination. ${ }^{11}$ Importantly, obesity in childhood tends to persist into adolescence and adulthood, with $67 \%$ of obese children growing up to be obese adolescents and $70 \%$ of obese adolescents in turn growing up to become obese adults. ${ }^{11}$ While the causes of childhood obesity are complex, one of the contributing factors is the overconsumption of energy dense foods, that is, foods high in fat, salt and sugar, such as most snack foods. ${ }^{11,12}$ Parents are mainly responsible for determining the foods that young children eat. ${ }^{11}$ They determine which foods are offered, the portion sizes and the frequency of eating occasions. $^{11,13}$

In other study of our group, we provide the first evidence that a significant proportion of the variability of cardiovascular risk factors is explained by genetic factors in a sample of 1,666 individuals in 81 families ascertained randomly from a highly admixed population 
of a city in a Brazilian rural area in Baependi. ${ }^{1}$ Heritability estimated for cardiovascular traits in the Brazilian population are high and not significantly different from other studied worldwide populations.

On the other hand, overweight and obesity are undermining the quality of life of children, adolescents and adults in many countries. A significant proportion of Brazilian adolescents have alterations in their plasma lipids with high prevalence of low HDL cholesterol and hypertriglyceridemia, especially in Brazil's North and Northeast regions. ${ }^{14}$ The prophylaxis of these conditions consists in guiding, from the beginning of childhood, a healthy diet, rich in fiber, incentive to practice physical exercises and reduction of sedentary activities. ${ }^{15}$

Different of the More and Less Swedish Study based on positive parenting, ${ }^{16,17}$ our study takes into account the power of children and adolescents to transform their lifestyles and their parents through a very enjoyable active school methodology that will allow these students to learn and acquire healthier eating habits and increase their physical activity, in addition to teach them for their families. Using puppets (named Insulin, Pancreas, Heart and so on) we can teach about healthy lifestyle, hygiene habits and prevention of epidemic diseases. Children and adolescents can help to change life style of all family by explaining to parents and brothers what they learned in the play presentation.

The evaluation of the program by the parents showed a high approval rate with changes in the habits of the whole family, more intense than the one observed in the request of the doctor to the member when it was diagnosed overweight or obesity, or even diabetes or hypertension.

\section{Conclusion}

It can be possible, rewarding and non-expensive to carry out projects for health promotion and prevention of diseases, mainly chronic non communicable diseases, involving children and adolescents and adults, when there is a linkage of research, teaching, care, public policy and many sectors in a city. However, the effectiveness of these actions may be proven in the evaluation of this population in the course of a few years with a greater control of the risks of cardiovascular diseases.

\section{Acknowledgements}

Universidade Antonio Carlos (UNIPAC-Juiz de Fora) for providing support to keep the group making the plays presentations in urban and rural area of Baependi town, for two consecutive years.

\section{Conflicts of interest}

The authors declare that there is no conflict of interest.

\section{Funding}

None.

\section{References}

1. De Oliveira CM, Pereira AC, de Andrade M, et al. Heritability of cardiovascular risk factors in a Brazilian population: Baependi Heart Study. BMC Med Genet. 2008;9:32

2. Egan KJ, von Schantz M, Negrão AB, et al. Cohort profile: the Baependi Heart Study-a family-based, highly admixed cohort study in a rural Brazilian town. BMJ Open. 2016;6(10):e011598.

3. Giolo SR, Pereira AC, de Andrade M, et al. Evaluating gene by sex and age interactions on cardiovascular risk factors in Brazilian families. BMC Med Genet. 2010;11:132.

4. Horimoto AR, Giolo SR, Oliveira CM, et al. Heritability of physical activity traits in Brazilian families: the Baependi Heart Study. BMC Med Genet. 2011;12:155.

5. Horimoto AR, Oliveira CM, Giolo SR, et al. Genetic analyses of smoking initiation, persistence, quantity, and age-at-onset of regular cigarette use in Brazilian families: the Baependi Heart Study. BMC Med Genet. 2012;13:9.

6. Ruiz Giolo S, Pereira AC, de Andrade M, et al. Genetic analysis of ageat-onset for cardiovascular risk factors in a Brazilian family study. Hum Hered. 2009;68(2):131-138.

7. Dietz WH. Health consequences of obesity in youth: childhood predictors of adult disease. Pediatrics. 1998;101(3 Pt 2):518-525.

8. Ogden CL, Carroll MD, Kit BK, et al. Prevalence of childhood and adult obesity in the United States, 2011-2012. Jama. 2014;311(8):806-814.

9. Pandita A, Sharma D, Pandita D, et al. Childhood obesity: prevention is better than cure. Diabetes Metab Syndr Obes. 2016;9:83-89.

10. Australian Health Survey: First Results, 2011-2012. Australian Bureau of Statistics. 2012.

11. Samantha B Boots, Marika Tiggemann, Nadia Corsini, et al. Managing young children's snack food intake. The role of parenting style and feeding strategies. Appetite. 2015;92:94-101.

12. Pearson N, Salmon J, Crawford D, et al. Are parental concerns for child TV viewing associated with child TV viewing and the home sedentary environment? Int J Behav Nutr Phys Act. 2011;8:102.

13. Ventura AK, Birch LL. Does parenting affect children's eating and weight status? Int J Behav Nutr Phys Act. 2008;5:15.

14. Faria Neto JR, Bento VF, Baena CP, et al. ERICA: prevalence of dyslipidemia in Brazilian adolescents. Rev Saude Publica. 2016;50(Supp1 1):10s.

15. Jimenez DE, Aschbrenner K, Burrows K, et al. Perspectives of Overweight Latinos with Serious Mental Illness on Barriers and Facilitators to Health Behavior Change. J Lat Psychol. 2015;3(1):11-22.

16. Ek A, Chamberlain KL, Ejderhamn J, et al. The More and Less Study: a randomized controlled trial testing different approaches to treat obesity in preschoolers. BMC Public Health. 2015;15:735.

17. 4364.0.55.003-Australian Health Survey: Updated Results, 2011-2012. Australian Bureau of Statistics. 2013. 